\title{
Colorectal Sessile Serrated Adenoma/Polyp
}

National Cancer Institute

\section{Source}

National Cancer Institute. Colorectal Sessile Serrated Adenoma/Polyp. NCI Thesaurus. Code C83176.

A polyp that arises from the colon or rectum. It is characterized by the presence of serrated glands and the absence of generalized dysplasia. Some authors have suggested that it is a precursor lesion for some colorectal adenocarcinomas with microsatellite instability. 